\title{
English for Occupational Purposes through Second Life: Promoting Interaction, And Professional Training
}

\author{
María José Naranjo \\ Department of English Philology \\ University Centre of Merida \\ University of Extremadura \\ Avenue Santa Teresa de Jornet 38, 06800, Mérida, Badajoz \\ Spain
}

\begin{abstract}
Nowadays, technology plays a fundamental role in our lives and consequently in the field of education, as well. If the appearance of the Web 2.0 contributed to transform learners into more active users of their acquisition process, there are tools such as virtual worlds which enhance interaction and help to develop computer-mediated communication in queasy real environments. In this context, our aim is to present a study carried out with English for Occupational Purposes (EOP) students attending an online course run through the management platform Moodle and where final communicative tasks are developed in the virtual world (VW) of Second Life (SL). The suitability to use virtual environments for language learning and professional training is measured by the completion of a survey analysis with course participants.
\end{abstract}

Keywords: EOP courses, communicative tasks, interaction, professional training, virtual worlds.

\section{Theoretical Background}

Despite the increasing incursion of information technology, the development of students' L2 communicative competence in e-learning environments remains a big challenge. Among the plethora of platforms, technologies and tools, Multi-User Virtual Environments (MUVEs) have been subject to a continuous research in the field of language learning (Deutschmann et al., 2009; Sadler, 2012; Thomas, 2013; Passfield-Neofitou et al., 2015; Rico and BravoFerreira, 2018).

Virtual worlds (VWs) are interactive platforms, a kind of computerized social networks in which an avatar, manipulated by the user behind the screen, moves around the environment, interacting, written or orally, with other in world inhabitant. Interaction takes place in real-time and can be hold in private or in public spaces, individually and in groups (Sajjanhar, 2012). Users have also the chance to communicate with automated avatars, the so-called bots, online citizens that are mainly used to greet newcomers, detect spammers, invite inhabitants to join groups and even to promote students' interaction (Palomo et al., 2015) getting involved in real-time conversational tasks, training which in some cases can also help to reduce students'anxiety in speaking (Grant, S et al. 2013).

But besides the potential of SL to practise and improve competences in foreign languages, we should mention the inherent feature of these virtual environments to develop professional training (Zheng et al., 2005; Edwards et al., 2008; 2009; Love et al., 2009; Rico and Bravo-Ferreira, 2018).

In this line of research, our aim is to present a qualitative study about the convenience of using virtual worlds for both language learning in English for Occupational Purposes and professional training in the field of tourism. The survey is measured by a set of questions to gain insights on the motivation and effectiveness portrayed in the completion of interactive tasks in SL to develop the linguistic and professional competences needed in a varied simulation of their future workplace.

\subsection{Communicative tasks and professional training in virtual worlds}

The process for diving into participation in a virtual world can be carried out in a variety of formats but always emphasizes the convenience of small groups and, specially, the application of role plays, a well-known learning technique in which students assume a given situation, acting it out and simulating reality from a holistic perspective (Au, 2008, Walsh, 2015). For the purpose of second language learning, the application of role-plays involves avatars and residents who are able to increase student motivation levels through intensive and stimulating tasks which may involve different skills and competences. 
But why do VWs reveal themselves as an adequate bet to develop simulations which promote language, cultural and professional competences by means of online instructions? Among other main features, virtual worlds:

- facilitate learning by doing, promoting users (avatar's) autonomy,

- enable the completion of real-life tasks, enabling the simulation of professional practices,

- allow learners to visualize powerful learning scenarios, online settings which may promote active engagement,

- promote autonomous and active learning where trainers act as facilitators of learning more than traditional instructors,

- foster self-assurance to overcome linguistic barriers and the fear of speaking in public.

\section{The Study: Objectives and Method}

It is our purpose to research the suitability of applying VWs in the training process of vocational oriented teaching, training in which learners' profile presents specific features, needs and wants. In this line, we pose the following objectives: (1) to gain insights on the motivation portrayed in the completion of real-life interaction tasks in English for vocational purposes through SL, and (2) the perception of how it can contribute to develop the linguistic needs, culture and professional training needed in their future workplace.

To cover the aims of the study, carried out with a group of adult learners taking an online 5 unit EOP course in the field of tourism and delivered through the management platform Moodle, we designed a set of additional communicative tasks at the end of each unit to be completed in Second Life (see content and units section 2.2).

\subsection{Population}

The group was composed by 40 adult students, 26 females and 14 males. They were basically unemployed or just with temporary or part time jobs, looking for a position in the tourist sector (tourist guides, hotels, travel agencies, etc.). None of them had higher or university degrees but secondary or vocational training certificates. The English level required to be enrolled was pre-intermediate (A2), according to the European Framework of Reference for Languages (CEFR). None of them held official language certification, a common situation in this target group; most had acquired their current level from other face-to-face (ftf) courses, professional practice and some grammar rules and vocabulary learnt during their primary and secondary school periods.

\subsection{Content and Units}

The online proposal was divided into 5 units in Moodle plus a final communicative task in Second Life, all related to the tourism and hospitality sector to which the course was focused. Units were named as follows

Unit 1. A survey: Personal qualities / skills for jobs in Tourism.

Unit 2. Good morning, can I help you?

Unit 3. Travelling abroad: Trips, hotels and flights reservation.

Unit 4. Eating \& going out: Speaking about gastronomy and other cultural elements.

Unit 5. A guided tour: A historical walk around the town.

Each unit deals with real life situations students will probably have to face up when enrolling in the compulsory trainee period they need to accomplish or in the professional development of tasks (guiding around towns and cities, at the hotel and travel agencies, culture and habits, etc.).

\subsection{Communicative Tasks: Role Plays in SL}

As said, all the units included a final task in SL where students, divided into pairs or into $3 / 4$ group of students, were asked to develop a set of steps conducting to a final task which integrated skills and competences presented in the different units. The description of tasks is summarized below:

1. Debate in groups of $3 / 4$ the main competences to work successfully in the tourist sector abroad.

2. In group of $3 / 4$ students, learners are asked to act as travel agent dealing with clients' reservation, providing information and helping the guest through all the reservation process.

3. Students are asked to imagine themselves working at a specific hotel. They have to show it to the guests, describing its main facilities and rooms. Interaction was made through oral and written chat.

4. Speaking and advising about culture and gastronomy: eating and drinking habits.

5. Mini project: research about a city and describe it.

All participants in the training course underwent a total of 5 units in Moodle (10 hours each unit) plus the aforementioned communicative task in Second Life, whose learning session' time limit was minimum 2 hours ( 1 offline to prepare the session plus 1 hour online to interact and receive teacher's assessment), time devoted to L2 learning and professional training among other students and peers. 


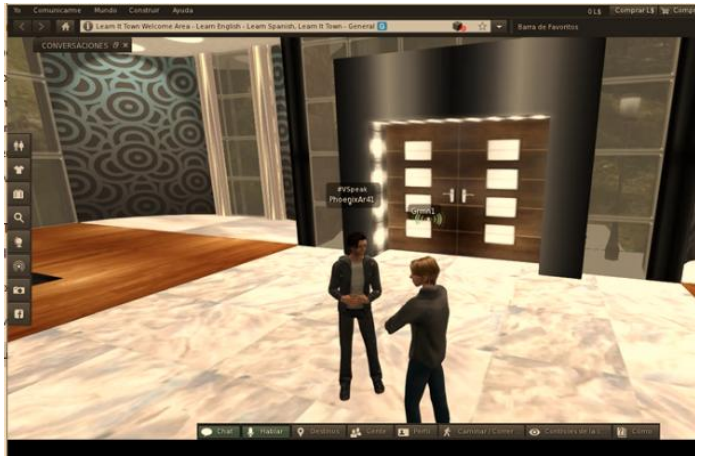

Figure 1. In a hotel reception.

Giving information to a client

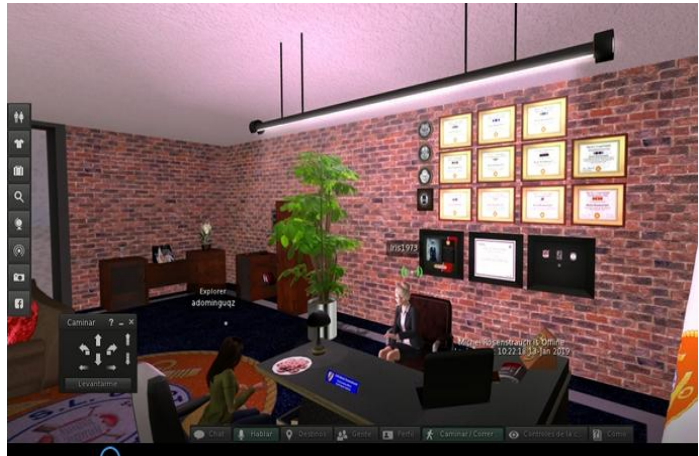

Figure 2. In a travel agency.

planning a travel

Participants received feedback on their performance, emphasizing how to improve and viewed a detailed assessment, according to an evaluating rubric - general content, language, task authenticity and non-verbal aspects- at the end of each assignment.

\section{Results}

At the end of the pilot experience participants completed a six questions survey to answer the objectives under study: measuring the attitudes towards the virtual learning environment and potentialities of the virtual world for language learning and professional training. Some of the main findings are summed up below. From the whole group that took the course, only 34 responded to the questionnaire, due mainly to availability to complete the survey and some technological limitations. The course duration was 2.5 months, from October to December, 2017.

Regarding the virtual learning environment, participants were first instructed and trained to ease the course navigation, for that purpose guidelines were created to inform them about the technological equipment and necessary applications to install a MUVE. Additionally, instructions to log in, along with a basic guide to create an avatar, tools available such as text and voice chat. Finally, participants were given instructions in a group in-world session about how to carry out role plays, interact with other users, how to record interactions or explore new sites or create different spaces.

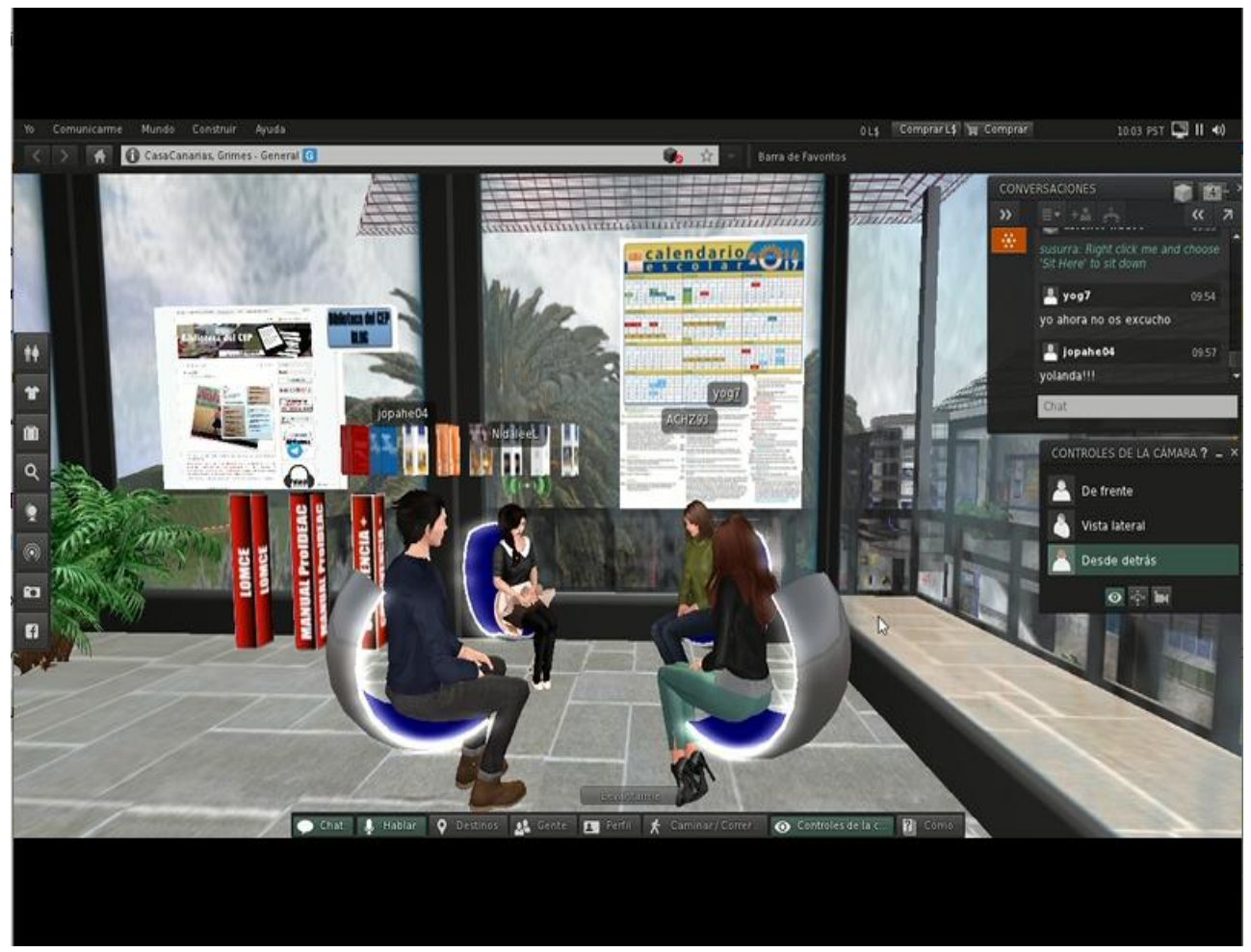

Figure 3. Group training session with instructors 
Very positive comments were given about this training session, devoting time to explain the functioning of the platform and the basic guidelines seem to be effective in non-technological native learners.

\subsection{Objective 1. Previous experience and motivation}

To get an overview about the previous experience and how motivated and engaged they felt by immersing themselves in the virtual world or second life where the speaking module was the highlight of the course, a set of 3 questions were posed and analyzed regarding: their previous experience (Q1.1), motivation and personal attitude to learn through this immersive virtual world (Q1.2). And a general question (Q1.3) which detailed if they would be interested to repeat the experience.

On the basis of the results:

Q1.1 Asking about their previous experience in SL, 96\% of the students who answered the survey (32 students) had no experience with SL (Graph 1)

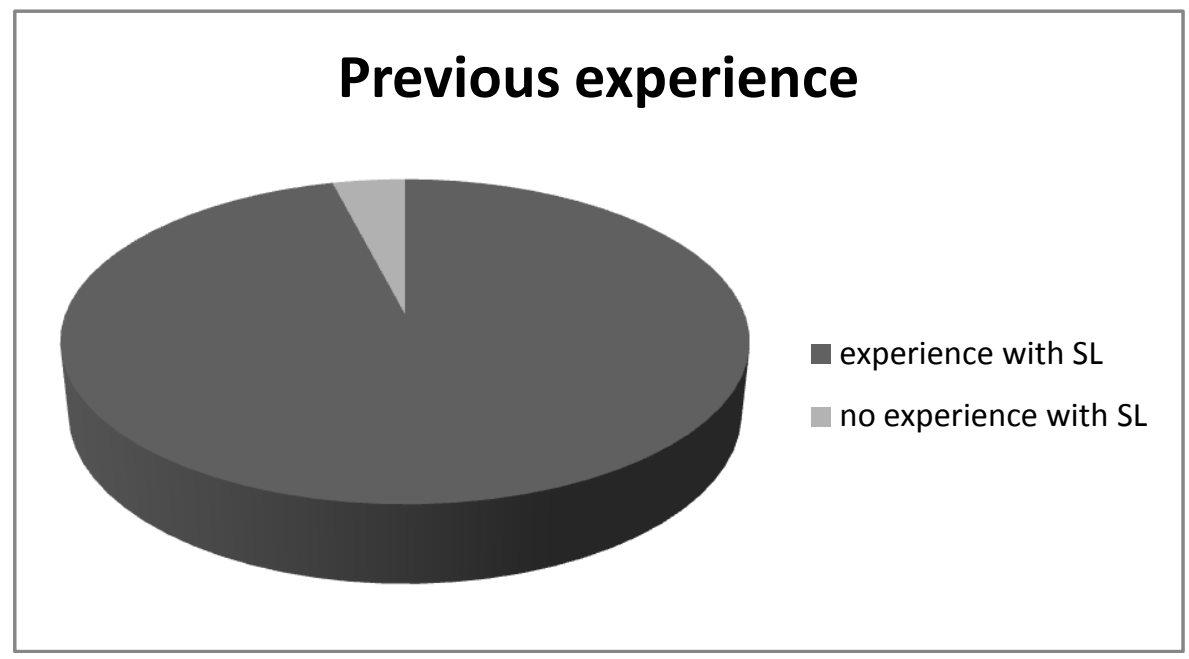

\section{Graph1. Question 1: Previous experience}

Even more than $75 \%$ have not even heard of it before the instruction. The remaining percentage admitted they had some type of previous contact though not in a formal learning proposal like that (Graph 2).

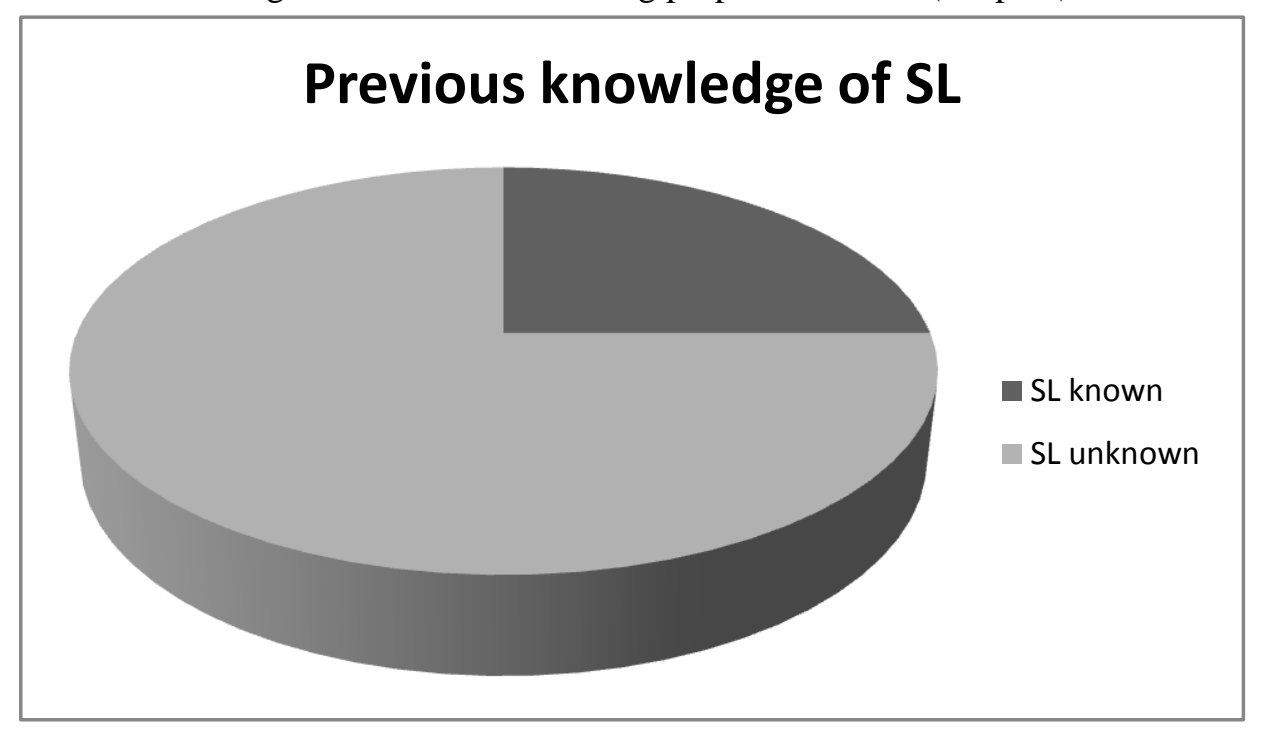

\section{Graph2. Question 1: Previous knowledge of SL}

Considering the feedback given, no negative comments were stated about the management of the virtual platform or the handling of it. Despite the running easiness, there exit gaps about the internet connection, speed, the graphic card necessary for an essential runout of the programme, or the high cost of hardware for higher-end virtual reality experiences. 
Q1.2 As for their personal attitude towards learning English through computer support has increased with SL, 32\% of the students admitted the interest in learning had not increased from the virtual world interaction; 45\% assumed they experienced "some" motivation towards the new tool, and $23 \%$ answered that they felt "a lot" of motivation. The game like teaching style, the simulation of real tasks and the interaction were the reason said by those who shown more positive comments. Results are shown in Graph 3.

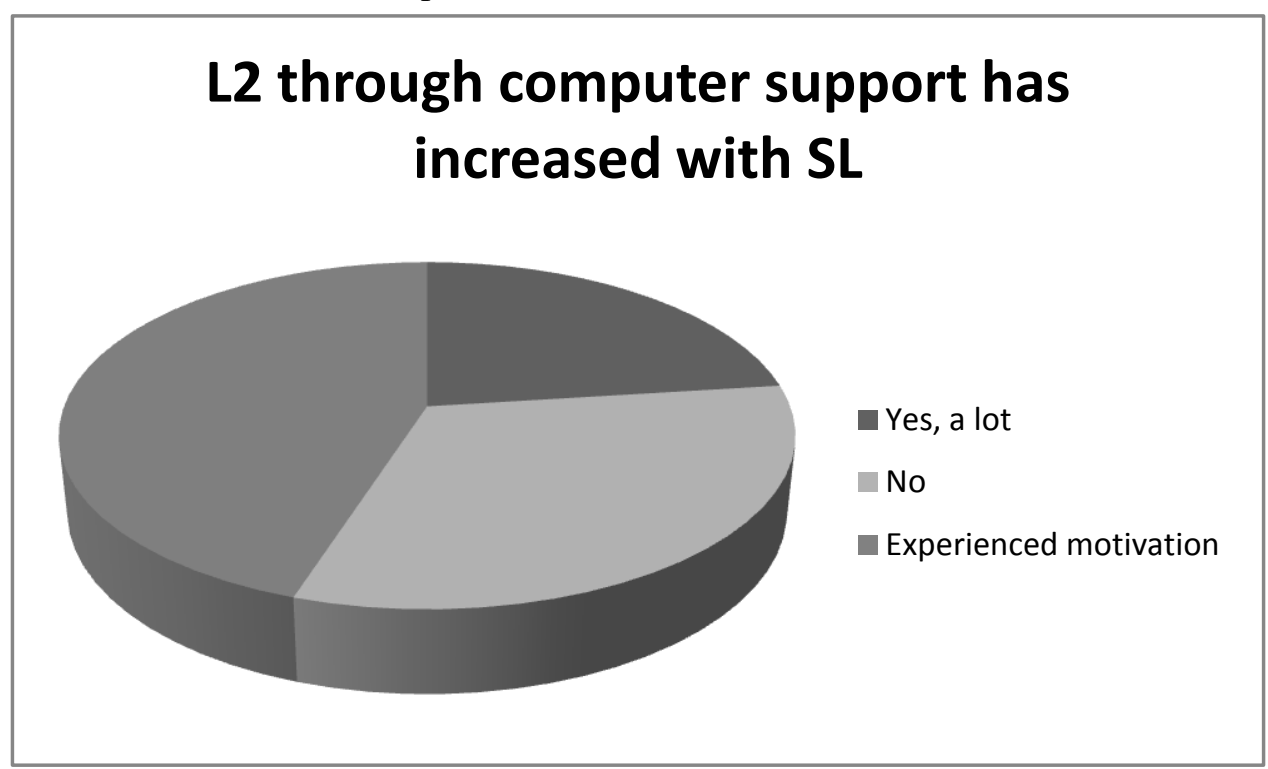

\section{Graph3. Question 2: Learning English through computer support has increased with SL}

Q1.3 In this sense, being asked if they would like to repeat this way of learning through computer support and SL for the final tasks, more than two thirds, $75 \%$ of the students answered "yes", against $25 \%$ of negative answers ("no"): These figures suggest that a vast majority of students felt motivated and enjoyed this online teaching proposals and activities.

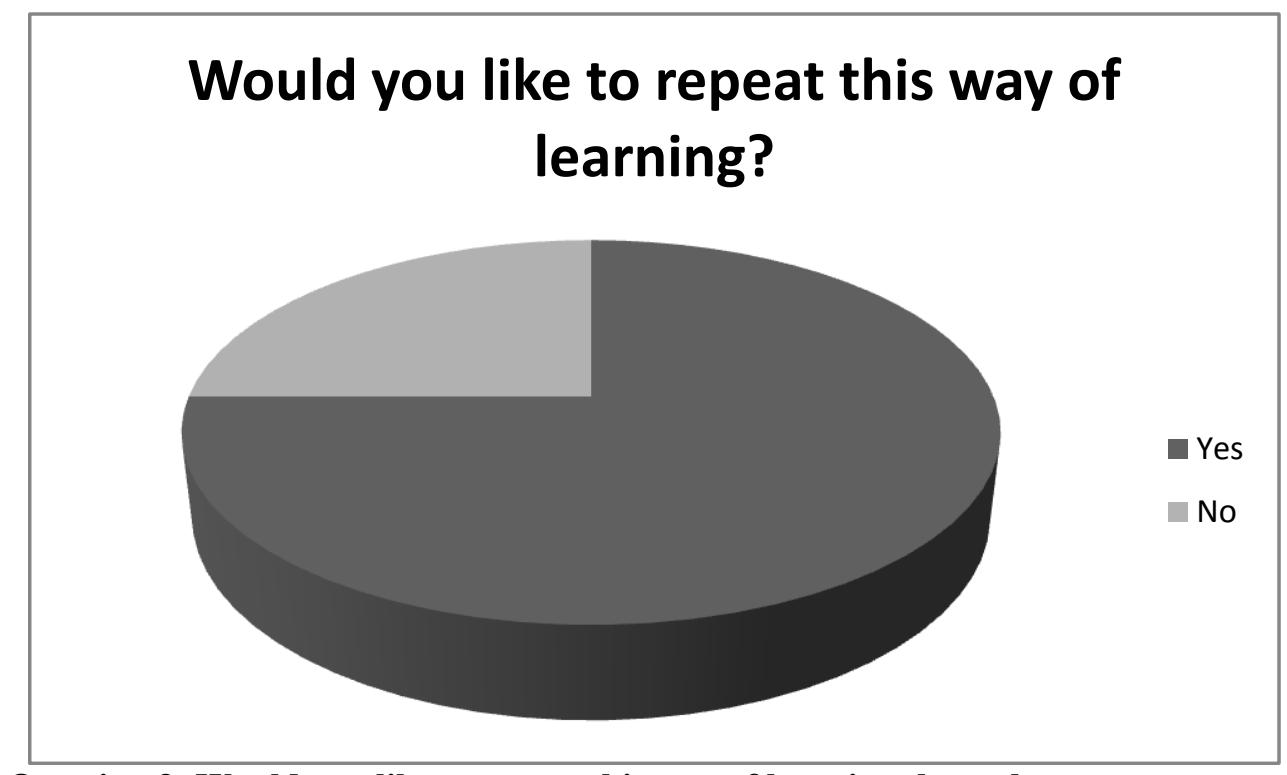

Graph4. Question 3: Would you like to repeat this way of learning through computer support and SL

Undoubtedly, novelty and motivation have been key factors in this teaching experience, encouraging participants to get involved in the learning process. They developed an online immersive training difficult to reproduce in other elearning, even face to face, contexts. The motivation is seen in the overall opinion about the platform, their implication and completion of the proposed assignments, representing good value to develop linguistic and professional competences.

\subsection{Objective 2. Contribution to their learning experience}


Learning experience refers to the linguistic and professional competences users receive to carry out the work in their future workplace.

In detail, their answers to the last 3 questions reveal the following results:

Q2.1. The first question enquired about SL contribution to the students' learning experience in general - language and professional training (SL has contributed to my learning experience...).

The results show that $30 \%$ of the students answered they experienced a no relevant contribution of SL in their overall learning experience (language or professional training), whereas $48 \%$ admitted it had "a little" or "some" influence, mainly due to motivation and novelty. $22 \%$ declared it had "High" influence on their overall learning (see graph 5).

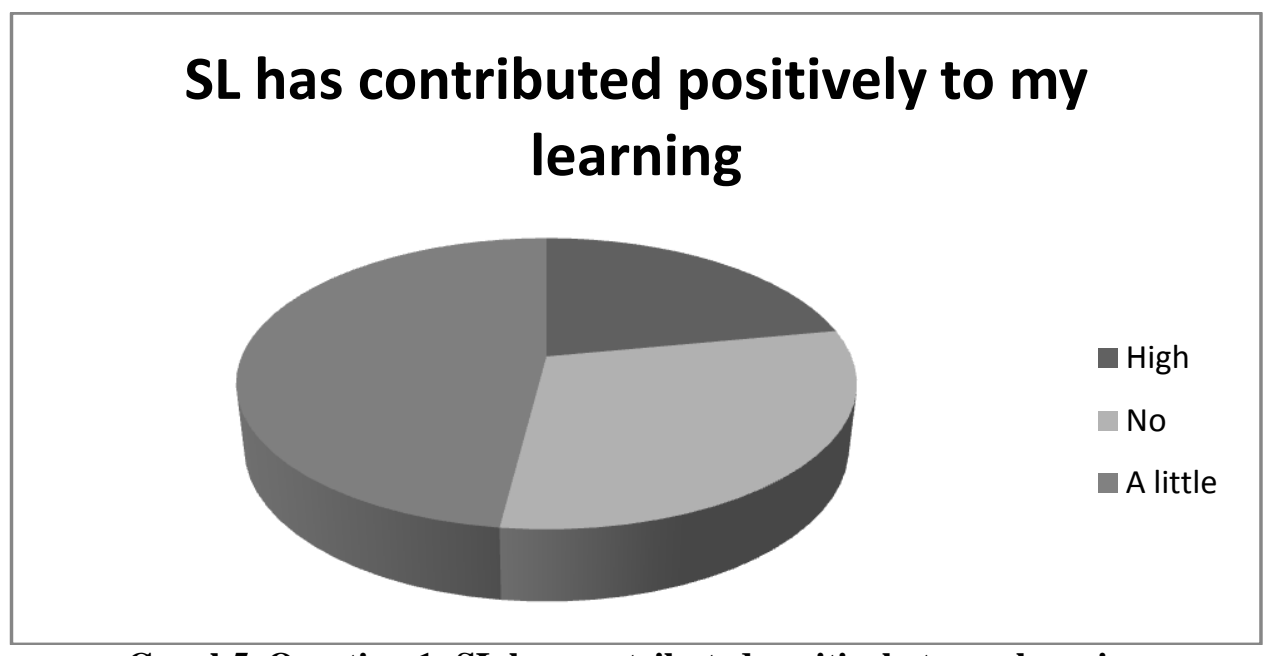

Graph5. Question 1: SL has contributed positively to my learning

If we take into consideration positive responses 'High' and 'A little' which reach a total of $70 \%$, we can state that most students assume the VW to be the trigger of the language learning acquisition and professional training to develop their future jobs. We all know that learning today has expanded far beyond the theoretical content shown in books and in class activities. In our global society, learning includes creating new understanding and training, and for our EOP proposal, Second Life seems to be an appropriate option, opening an endless bunch of in world possibilities. In line with other studies, as seen in the theoretical framework, the results show that the advantages of learning in immersive 3D environments are many: the educational platform is engaging, eco-friendly and it works, encourages social interaction, motivating, self-paced learning to suit all learning styles, appealing environments, experiences authentic language use, overcomes physical and linguistic barriers, to name but a few.

SL also enables students to work together synchronously and asynchronously, fosters autonomous learning, simulating complex processes in the physical world. Avatars can also take on different roles to enhance professional training, and the teacher simply serves as a guide to help and monitor the learning environment. Users analyse and solve problems to achieve the best possible outcomes, and this is in line with Mroz (2015) who examines the emergence of L2 critical Thinking (CT).

Q2.2. In detail students were asked about the skill they thought they had improved the most through SL exposition (language skills related to their professional competences within the tourist sector). From the options, we get the following results:

\begin{tabular}{|l|l|l|l|}
\hline Skills & No improvement & Slightly & Noticeable \\
\hline Grammar & $88 \%$ & $11 \%$ & $1 \%$ \\
\hline Vocabulary & $24 \%$ & $61 \%$ & $15 \%$ \\
\hline Pronunciation & $39 \%$ & $55 \%$ & $6 \%$ \\
\hline Reading & \multicolumn{1}{|c|}{$77 \%$} & $22 \%$ & $1 \%$ \\
\hline Writing & $67 \%$ & $30 \%$ & $3 \%$ \\
\hline Listening & $37 \%$ & $55 \%$ & $8 \%$ \\
\hline Speaking & $34 \%$ & $55 \%$ & $11 \%$ \\
\hline Culture for their & $28 \%$ & $51 \%$ & $21 \%$ \\
\hline $\begin{array}{l}\text { Training juture jobs } \\
\text { futur }\end{array}$ & $47 \%$ & $29 \%$ \\
\hline
\end{tabular}

Table1. Skills improved 
As indicated in the table 1, the integration of different skills is possible in English language teaching through SL. According to the data analysis, SL helps learners improve both their speaking and their listening skills, and cultural awareness as well. What is found the most interesting is the professional support and training for their future jobs, this can be justified having into consideration their profile, users were basically unemployed and looking for a position in the tourist sector (tourist guides, hotels, travel agencies). In addition, learners experience a less stressful environment in the virtual world in terms of language use, and they do not report a significant inherent level of technical related anxiety that can be demonstrated in a real world situation.

The language skills and aspects that SL might contribute less to teaching in this study are grammar, reading and writing. Reasons for these weaknesses can be attributed to the choice of writing and speaking in order to communicate with the other visitors. If they notice more improvements in speaking and listening, as stated before, consequently less practice was given to writing and reading, which, in fact, are more emphasized in the different activities of the Moodle platform.

Q2.3. When asked whether they felt more confident about their role as a professional within the tourist sector in a future job, after having completing the final task (I feel more confident about my role in a future job), the following percentages are found.

- $28 \%$ of the students answered "no",

- $49 \%$ answered "a little" \& "some" confidence when developing tasks at the workplace,

- and $23 \%$ declared that they will feel "a lot" of confidence after finishing this course

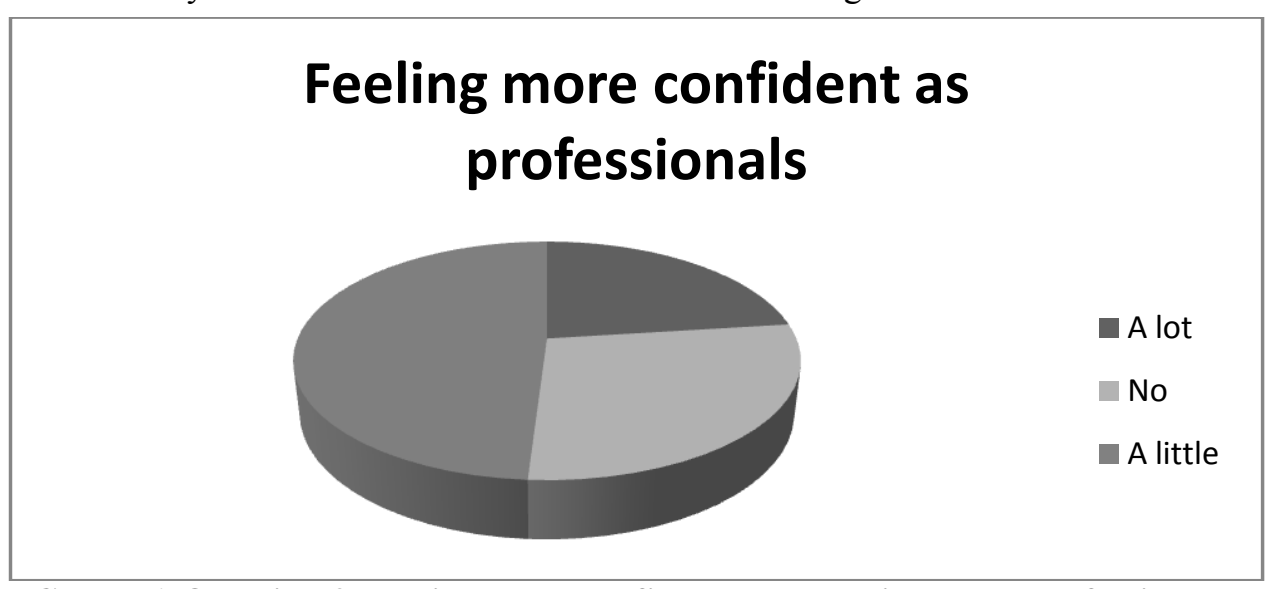

Graph 6. Question 3. Feeling more confident about their role as professionals.

The authenticity and resemblance between real-life tasks (those learners would do in everyday life at work) and the scenario provided by the platform makes of SL an appealing platform for teaching languages for specific purposes, the development of language competences in real life for that specific purpose. Further, SL might be used as means of teaching practice and continuous professional development, especially role playing scenarios to engage learning.

\section{Conclusions}

The results of this study suggest that virtual worlds could offer a new education pedagogy to enhance vocational languages learning outcomes beyond those provided by more traditional online or face-to-face professional development activities. As a conclusion for the first objective, due to its novelty, interactivity of the platform, motivating environment, SL is a valuable resource to lower student anxiety and increase their motivation to learn a foreign language. Regarding the best valued skills presented in the second objective, we highlight: the oral communication, the importance of the oral simulation reveals as an important aspect of learner-learner interaction which enhances Oral Production (Speaking) in the SL Classroom. Another benefit of SL is attached to the authentic language use within the platform. Additionally, the results indicate that the teaching of speaking and listening skills is fostered in an integrated way in SL, and the teaching of writing and other skills like grammar are also fostered in the Moodle platform.

Additionally these skills (reading and writing) can be improved by integrating some writing tasks among avatars or creating virtual spaces aimed at reading and writing. It is also worth noting that despite their low improvement in writing and reading in SL, these skills were also worked on in the Moodle platform. The final task of each unit was devised as communicative, thus it is logical the enhancement is focused on the oral productive ability. 
The formation of socio-cultural competence in foreign language teaching also plays an important role in SL. The ability to visualize and move through queasy real life environment and the chance to connect and interact with people across the world, providing newer cultural experiences (cultural peculiarities of English-speaking countries, their habits, traditions, standards of behaviour) that would otherwise be difficult in the traditional ftf classroom.

Undoubtedly the ability to develop authentic activities which provide the opportunity for students to analyse the environment and complete the task is highly valued by the participants. In this sense, Second Life can enable users to analyse and create learning experiences that resemble real-world activities and scenarios. In short and in line with Chien-pang Wang et al. (2019), our preliminary results show a noticeable motivation orientation towards the platform, overall linguistic gains, suitability to promote cultural awareness and relevant percentages as a tool to train learners in professional tasks.

\section{References}

Au, W. J. (2008). The Making of Second Life. Notes from the New World. New York, New York: HarperCollins Publishers.

Chien-pang Wang, Yu-Ju Lan, Wen-Ta Tseng, Yen-Ting R. Lin \& Kao Chia-Ling Gupta (2019). On the effects of 3D virtual worlds in language learning - a meta-analysis. Computer Assisted Language Learning, DOI: 10.1080/09588221.2019.1598444

Deutschmann, M., Panichi, L., \& Molka-Danielsen, J. (2009). Designing oral participation in Second Life: A comparative study of two language proficiency courses. ReCALL, 21(2), 206-226.

Edwards, P., Domínguez, E. \& Rico, M. (2008). A Second Look at Second Life: Virtual Role-play as a Motivational Factor in Higher Education. In K. McFerrin et al. (Eds.), Proceedings of Society for Information Technology and Teacher Education International Conference 2008 (pp. 2566-2571). Chesapeake, VA: AACE.

Edwards, P; Rico, M; Domínguez, E. Agudo, J.E. (2009). Second Language E-Learning and Professional Training with Second Life. In Collective Intelligence and E-Learning 2.0: Implications of Web-Based Communities and Networking (pp. 207-227). IGI Global. Information Science Reference, U Hersey, PA. USA.

Grant, S. J., Huang, H., \& Pasfield-Neofitou, S. (2013). Language learning in virtual worlds: The role of foreign language and technical anxiety. Journal of Virtual Worlds Research, 6, 1-9.

Gu, N., Gul, L. F., Williams, A., \& Nakapan, W. (2009). Second Life-A context for design learning. In C. Wankel \& J. Kingsley (Eds.), Higher education in virtual worlds: Teaching and learning in Second Life (pp. 159-180). Bingley: Emerald.

Love, E., Ross, S. C., \& Wilhelm, W. (2009). Opportunities and challenges for business education in Second Life. In C. Wankel \& J. Kingsley (Eds.), Higher education in virtual worlds: Teaching and learning in Second Life (pp. 65-82). Bingley: Emerald.

Mroz, A. (2015). The development of second language critical thinking in a virtual language learning environment: A process-oriented mixed-method study. CALICO Journal, 32(3), 528-553.

Palomo Duarte, M., Berns, A., Dodero J. M. and Ruiz Rube, I. (2015a). Análisis de interacción en entornos virtuales orientados al aprendizaje. In A. Fidalgo Blanco, M.L. Sein-Echaluce Lacleta and F. García-Peñalvo (Eds.). III Congreso Internacional sobre Aprendizaje, Innovación y Competitividad, CINAIC. Madrid, 2015 (pp. 597-601). Madrid: Fundación General de la Universidad Politécnica de Madrid.

Passfield-Neofitou, S., Huang, H., \& Grant, S. (2015). Lost in Second Life: Virtual embodiment and language learning via multimodal communication. Educational Technology Research and Development, 63, 709-726.

Rico, M. \& Bravo-Ferreira, P. (2018). Acquisition of language and intercultural competences in tourism and hospitality studies through active experimentation in Second Life. Teaching English with Technology, 18(2), 69-92.

Sadler, R. (2012). Virtual Worlds, telecollaboration, and language learning: From theory to practice. Bern: Peter Lang.

Sajjanhar, A. (2012). Virtual Worlds for Student Engagement. Creative Education, 3, 796-801.

Thomas, W. W. (2013). Incidental learning and virtual worlds. (Unpublished doctoral dissertation). University of Alberta, Alberta.

Walsh, S. (2015). Beyond the role-play-Re-thinking mediator education. Journal of Mediation \& Applied Conflict Analysis, Vol. 2, No2, pp.317-327.

Zheng, D., Brewer, R. A., \& Young, M. F. (2005, November). English language learning in a game-based Multi-User Virtual Environment: Quest Atlantis connects middle school students in China to the world. Paper presented at Webheads in Action Online Convergence. 